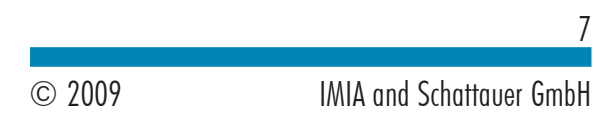

\title{
In Memoriam Steven A. Huesing (1944 - 2009)
}

\author{
R. Haux ${ }^{1}$, N. M. Lorenzi ${ }^{2}$, K.C. Lunn ${ }^{3}$, O. Rienhoff ${ }^{4}$, J. H. van Bemmel ${ }^{5}$ \\ 1 University of Braunschweig and Medical School Hannover, Germany \\ ${ }^{2}$ Vanderbilt University Medical Center, Nashville, TN, USA \\ ${ }^{3}$ Nanyang Technological University, Singapore \\ ${ }^{4}$ University of Göttingen, Germany \\ ${ }^{5}$ Erasmus University Medical Center, The Netherlands
}

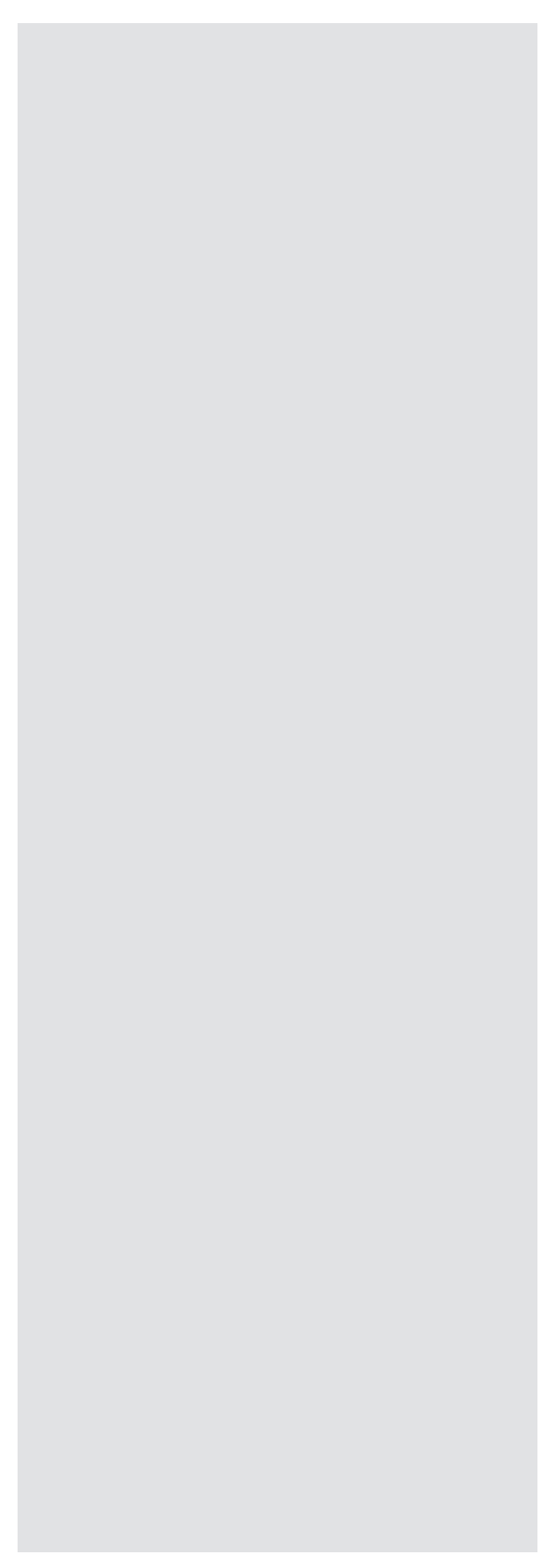

\section{Steven Was Always There}

On Sunday, April 12, 2009, Steven A. Huesing passed away.

Since 1997 Steven Huesing was Executive Director of IMIA - the International Medical Informatics Association [1]. In this prominent role he provided for many years significant and global contributions to the progress of our field. It was through his tireless work that IMIA has developed into the leading international association that it is today.

When coming in touch with IMIA, many colleagues first communicated with him. And often he remained the major link to our association. As indicated by the messages, IMIA received after his death, colleagues of all parts of our world deeply miss him [2]. The sentence "IMIA presidents and other officers were coming and going, and Steven was always there", taken from this book of condolence, describes so well how many of us valued and respected him.

Steven Huesing was born on September 8, 1944 in Bensheim, Germany. He moved to Canada with his mother and step-father, when he was 8 years old.

At the beginning of Steven Huesing's career in the 1960s, computers were still considered avant-garde and risky, even in a mainstream industry. Steven Huesing was a registered industrial and cost accountant. In 1967 he earned his CMA designation in at the University of Alberta. His interests in health informatics flourished, while he filled

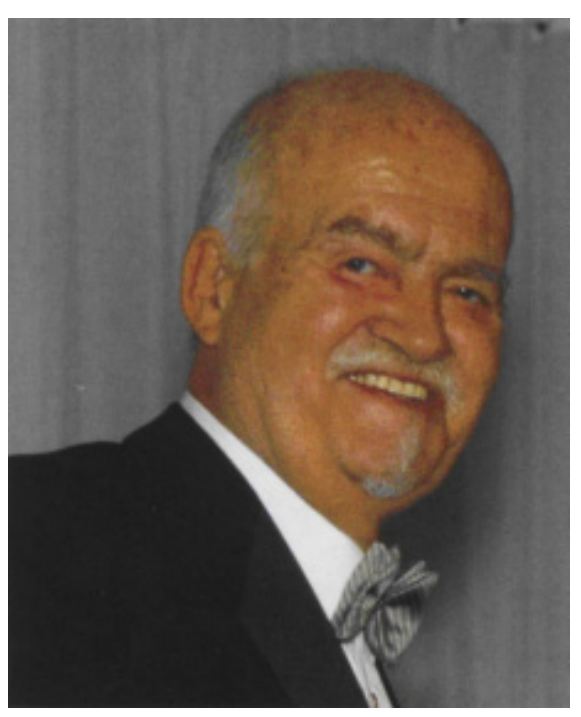

Fig. 1 Steven Huesing (1944 - 2009)

senior administrative $\mathrm{CFO}$ and $\mathrm{CIO}$ roles with hospitals and government. His many accomplishments included [3]:

- Serving Canada's Health Informatics Association $(\mathrm{COACH})$ in many capacities, including as Founding President (1975-78); Executive Director (1980-99), and editor of the COACH history book, covering 1975-2005.

- Being the only Canadian to serve as President of IBM's user group, Electronic Computing Health Oriented (ECHO) from 1983 to 1987.

- Starting Healthcare Information Management \& Communications Canada (HCIM\&C), the only health informatics magazine in Canada for 
many years. The magazine has been published since 1987 and just recently celebrated its "over 20 years of publishing" in a special tribute issue [4].

- Together with David Wattling, founding the Canadian Healthcare Information Technology Trade Association (CHITTA), now the healthcare division of the Information Technology Association of Canada (ITAC);

- Establishing the COACH Founding President's Award in 1983 to recognize and motivate outstanding health information science students at the University of Victoria. In 1999, COACH established the Steven Huesing Scholarship for students in health informatics or related programs at Canadian post-secondary institutions.

- Active involvement in developing health informatics curricula with several universities, colleges and associations.

Since the start of his career, in the 1960s, he has been a pioneer and ambassador to the advancement of computers and information technology in healthcare. Among the many recognitions of his contributions, he was honoured for his exceptional work with the prestigious Canadian Health Informatics Award for Lifetime Achievement [3].

In the next five sections those IMIA Presidents, who worked with Steven Huesing, will describe their personal memories.

\section{Otto Rienhoff, Germany, IMIA President 1995 - 1998}

With the first MEDINFO in Stockholm in 1974 IMIA became visible internationally. MEDINFOs in Toronto (1977), Tokyo (1980), Amsterdam (1983), Washington (1986), Being/ Singapore (1989), and Geneva (1992) followed. IMIA learnt that its success and growth was very much depending on the success of the MEDINFOs. However, the organization also discovered, that growing MEDINFOs need more and more long term interaction between the international program committee, the publication committee, the local organization committee, and the acting IMIA president and treasurer. It became clear that IMIA would not be able to grow without a missing link: an international office. The discussion of how to establish such a construct and how to find an appropriate candidate went on for several years. It became clear that only very few individuals have an international background, have substantial knowledge of medical informatics, and at the same time are socially acceptable in many cultures and want to do the job. In the very end of the selection process only two individuals remained on the short list - of which Steven Huesing was selected.

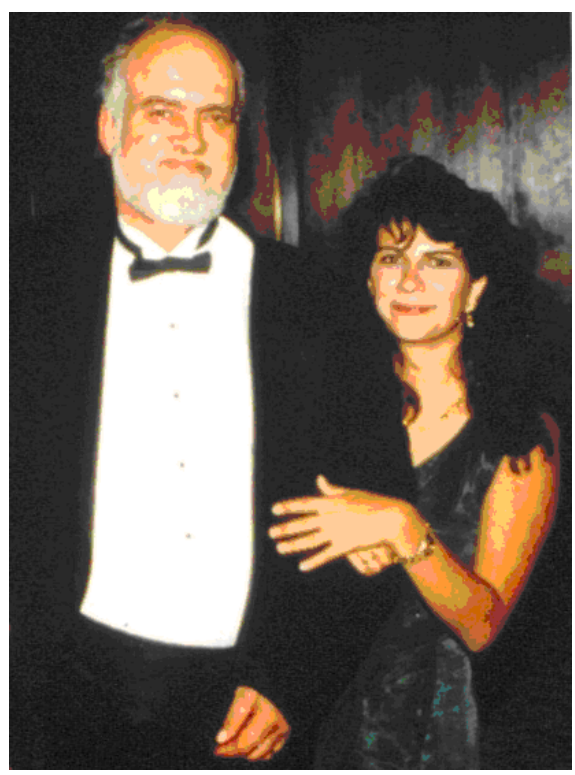

Fig. 2 Steven Huesing and his daughter Elaine at MEDINFO 1995 in Vancouver celebrating the biggest MEDINFO ever

A key element in the decision process was the major success of the 2nd Canadian MEDINFO in Vancouver, the biggest ever so far. During this major meeting it also became evident that Steven had a substantial help in his job by his daughter Elaine, who worked in his office and always was his right hand.
Elaine stayed in the background - but was a friendly, warm, and extremely competent constant back up.

The Huesing family office proved stable and extremely helpful during the next MEDINFO in Seoul in the midst of a financial crisis in South Korea in 1998. With my predecessor in the IMIA presidency, Marion Ball, we went through unbelievable ups and downs in the preparation process. The IMIA office proved to be of great help for the first time. Due to the impressive push of our colleagues the MEDFINFO became a major success - even financially despite the crisis.

The construct of the IMIA office was now waterproof. At the end of my presidency IMIA had not only an international office but an experienced director and a family back-up that allowed a strategic planning of growth, which had been unthinkable in the years before.

\section{Jan H. van Bemmel, The Netherlands, IMIA President 1998 - 2001}

During the years that I was IMIA President, but also before and after that time, I had many meetings and conversations with Steven. Most of them were not just professional, but also very personal. Let me recall some of my memories of these meetings.

\section{Dresden 1994}

Perhaps the most busy conversations about the future of IMIA took place during a Board and General Assembly meeting in 1994 in Dresden, Germany, where we made the first plans for a 'Permanent Office' for IMIA. It was the time when I was 'Vice-president for Services', which involved planning, publications, external relations and the like. During that time we laid the foundation for what was later to become Steven's Canadian office from which he served IMIA as Executive Director 
for well over 10 years. During the Dresden meeting I became very impressed by Steven's organizational capacities and his quiet way in handling difficult issues and in convincing people. At the Dresden meeting I also learned to know Elaine, Steven's no less gifted daughter, who during all the years gave him so much support.

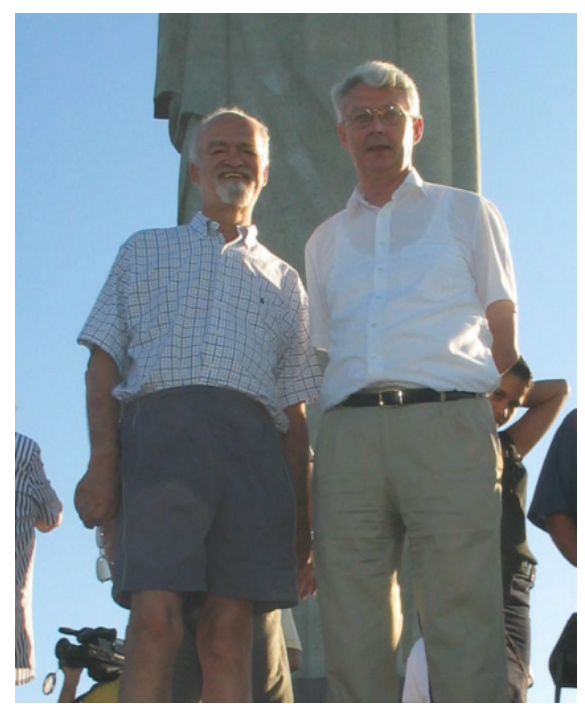

Fig. 3 Steven Huesing, June 2003 in Rio de Janeiro, with Jan van Bemmel

Let me mention one particular event in Dresden that I still remember vividly. First, I will sketch some background. The first time I visited Dresden, for a conference, was in 1973, some years before TC-4, the forerunner of IMIA, was established by François Grémy. These were still the dark years of the German Democratic Republic. The now beautifully rebuilt baroque Frauenkirche was still completely in ruins after the bombardment of February 1945 by the Allied Forces. The Stasi (a sort of East-German KGB) was omnipresent and, as I experienced, people that I met were afraid to speak out about their feelings. During the Sunday that I was in Dresden I attended a service in the Kreuzkirche that was still seriously damaged. I was deeply impressed by the pastor, who had the guts to criticize in his sermon the ruling communist party. During our IMIA meeting in
1994 I heard there would be a performance of Bach's Lukas Passion in the Kreuzkirche, by a Japanese choir that made a tour in Germany, coached by the famous German soprano Agnes Giebel. I went there with Steven and Jean-Raoul Scherrer. The music was most impressive, also given the historic site, and the choir sung the whole Passion by heart in German (!). After the performance both Steven and I had tears in our eyes and had a little conversation with the gifted female conductor of the choir. Steven was a very sensitive and sometime emotional person indeed.

\section{New Zealand 2000}

Another memory of working and travelling with Steven was during the Nursing Conference in Auckland in 2000. The country is most beautiful and Steven and I took a day off, hired a car, and went to Rotorua, a place with gigantic mud pools and geysers, because of the volcanic activity of that part of the world. Many times afterwards, Steven came back to this trip because we had long conversations on the nature around us and - I think and I hope - I opened his eyes somewhat further when looking at the wonders of nature. We discussed geothermal activity and solar activity, steam from the geysers and clouds in the sky, rock formation and the formation of stars and planets. Many such conversations gave rise to even deeper thoughts, such as, why are we on earth; what is the purpose of our lives? Again, I experienced Steven as a most sensitive and warmfeeling person.

Much more is to be said, but I have been given a finite number of lines only. I could have mentioned his stay in Rotterdam, also during a Board meeting, or our common trip by boat in Rio de Janeiro. Of this trip I have included a typical picture that I took on board of the sailing boat. This was Steven as he truly was: friendly and radiant. We miss him dearly and keep good memories of him.

\section{KC Lun, Singapore, IMIA President 2001 - 2004}

In his lifetime, Steven Huesing had made significant contributions to health informatics, not only within his own country, Canada, but also internationally, especially in his capacity as Executive Director of IMIA, a job he performed par excellence. His passion and commitment to the field are measured by the many accolades and recognitions that he had received over the years and the friendship and trusts that he had built within the health informatics communities worldwide.

My acquaintance with Steven dated back to 1995 when we met at MEDINFO 95 in Vancouver. Since then, our friendship had grown over the years through our involvement in IMIA, with him as Executive Director and me initially as IMIA Board Member, then Vice President (MEDINFO) and eventually President from 2001-04. Our friendship went beyond our IMIA terms as after I had relinquished my position on the IMIA Board, we continued to maintain contact with each other with occasional exchange of greetings and news through skype calls. I remember "skyping" with him soon after the passing of our mutual friend and IMIA colleague, Dr. Branko Cesnik and how we both felt a deep sense of loss for a long-time friend and IMIA comrade.

As the IMIA Executive Director during the term of my IMIA presidency, Steven's excellent grasp of the IMIA governance and financial position helped me to steer IMIA through some difficult years in the global economy. His extensive knowledge and network of contacts of the health informatics communities around the world also provided me with the strong linkages to connect with individuals and organizations to get my work done.

At many board meetings and general assemblies around the world, we often took time off to share news about our work, mutual friends and families over a pint of beer or a glass of wine 


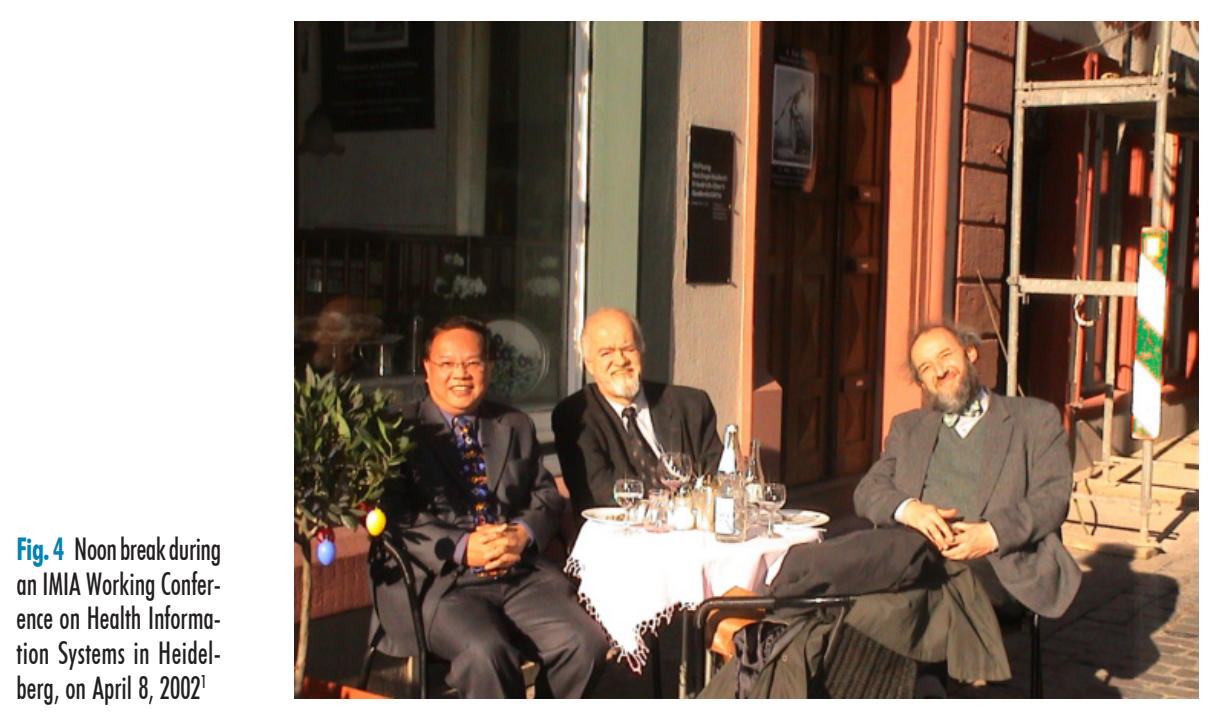

and, for me, these recollections help to bring back fond memories of my good friend, Steven Huesing.

\section{Nancy M. Lorenzi, USA, IMIA President 2004 - 2007}

In addition to being the IMIA Executive Director, Steven Huesing had a number of other IMIA roles. IMIA's connector! IMIA's protocol officer! IMIA's accountant! As well as IMIA's "hand holder" to name a few of the multiple roles that Steven assumed for IMIA.

I first met Steven at the Scientific Program Committee (SPC) meeting for the MEDINFO 1995 meeting in 1994 in Dresden, Germany. Two of Steven's daughters, Elaine and Christina, were at the meeting. Elaine was present as a business associate and Christina for exploring life's options. It was apparent from that early meeting that Steven was both very knowledgeable about association business and very inclusive of family in his efforts. During the SPC time in Germany, we laughed about figuring out how to purchase a ticket to ride a train to sorting out many complicated

From left: KC Lun, Steven Huesing and Reinhold Haux. issues that face all Scientific Program Committees. Even though the Canadians had less than 2 years to plan, MEDINFO 1995 in Vancouver, British Columbia was an outstanding success! It was $\mathrm{COACH}$ and Steven's company that organized the multiple elements of this conference. Many Huesing family members participated in multiple aspects of MEDINFO.

Through the years and my ever-deepening involvement with the IMIA, I Better Health staff. saw the many sides of Steven. From the professional side, he was the arbitrator of IMIA protocol, the container of IMIA history, the facilitator of IMIA disputes, and a person who accurately could take care of the roles and responsibilities of every IMIA board member who did not effectively deliver what he or she agreed to do. In other words, he became Mr. IMIA. As those of us on the Board said, "ask Steven", "email Steven", etc.

Steven was so proud of his children. His family came first! During our IMIA Board meetings, one or more members of his family accompanied him to gain a greater experience of the world. On one of the trips, my sister was travelling with me in Italy and I am positive by the end of the trip she was ready to adopt Steven's daughter who was approximately her own daughter's age. Steven was very easy to talk with, to share with, and to gain his opinion on many topics. Steven listened, he thought about the issues, and he offered suggestions or ideas that were extremely diplomatic. I enjoyed our face-to-face and telephone conversations, they were always warm and too short.

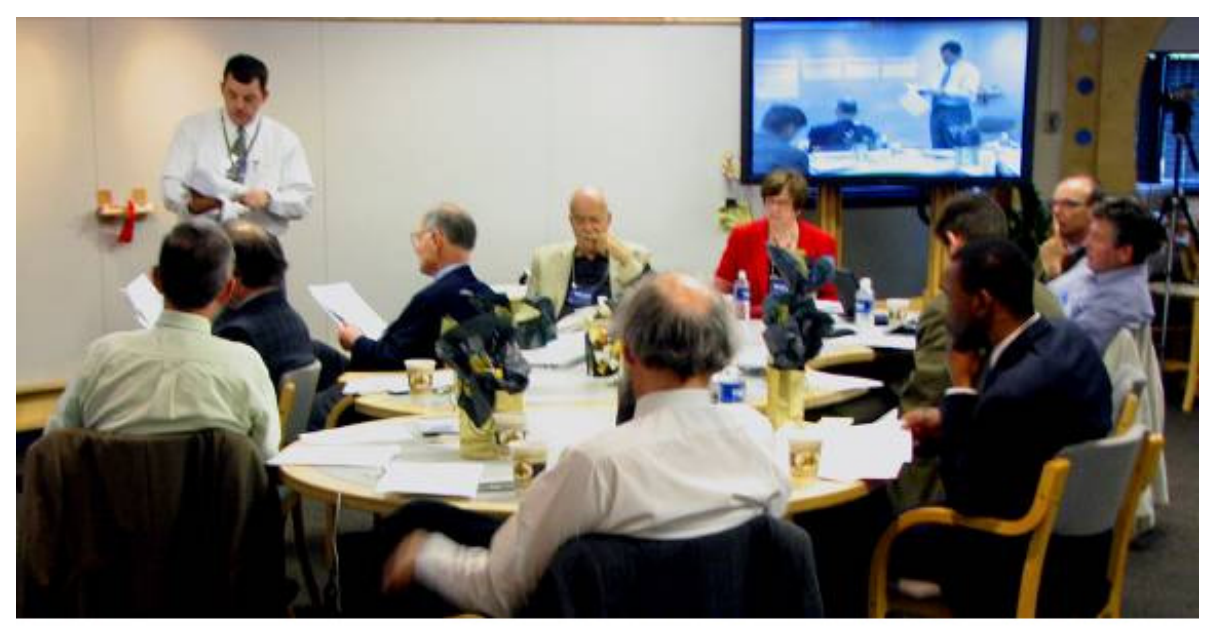

Fig. 5 Working on IMIA's strategic plan "Towards IMIA 2015" on April 12, 2007, at Vanderbilt University in Nashville²

2 IMIA Board members starting at the left and circling the table: Diamuid UaConaill, Hiroshi Takeda, Casimir Kulikowski, Steven Huesing, Nancy Lorenzi, Antoine Geissbuhler, Peter Murray, Fernando Martin-Sanchez, Ghislain Kouematchoua and Reinhold Haux. The standing person is a member of the Vanderbilt Center for 
Another side of Steven was that of learner. He wanted to learn and experience new ideas. While he was an accountant by education, he was willing to learn new skills including from some of us, who work in the social psychological side of informatics. This became more apparent during my IMIA presidency years. IMIA approached strategic planning with an open and inclusive process. Steven became more interested in process and involvement strategies. His creativity became more apparent as we used white-boards and flip charts for brainstorming and the planning steering group became very engaged in discovering the IMIA Possibility Framework [5].

With Steven's death, I feel I not only lost a colleague, but very dear friend.

\section{Reinhold Haux, Germany, IMIA President 2007 - 2010}

My memories of Steven Huesing start with MEDINFO 1995. It was a wellorganized conference and for conference participants like me it became soon clear that Steven was a major person for this success.

Since 1999 I have served on IMIA's Board, first as Vice-President for Services and now as President. During this time the professional collaboration with Steven began, became increasingly intensive and with the time personal friendship came up, too. During this time I learned that Steven was not only very well organizing and preparing all IMIA meetings. He was a key person for IMIA's growth and long term success. And was also a very important person in helping overcome critical situations.

Let me mention two examples. As IMIA Vice-President for Services I had the honour and pleasure to be co-editor of the IMIA Yearbooks 2000 - 2007, together with Casimir Kulikowski. It was a very time-consuming task, which I nevertheless very much enjoyed.

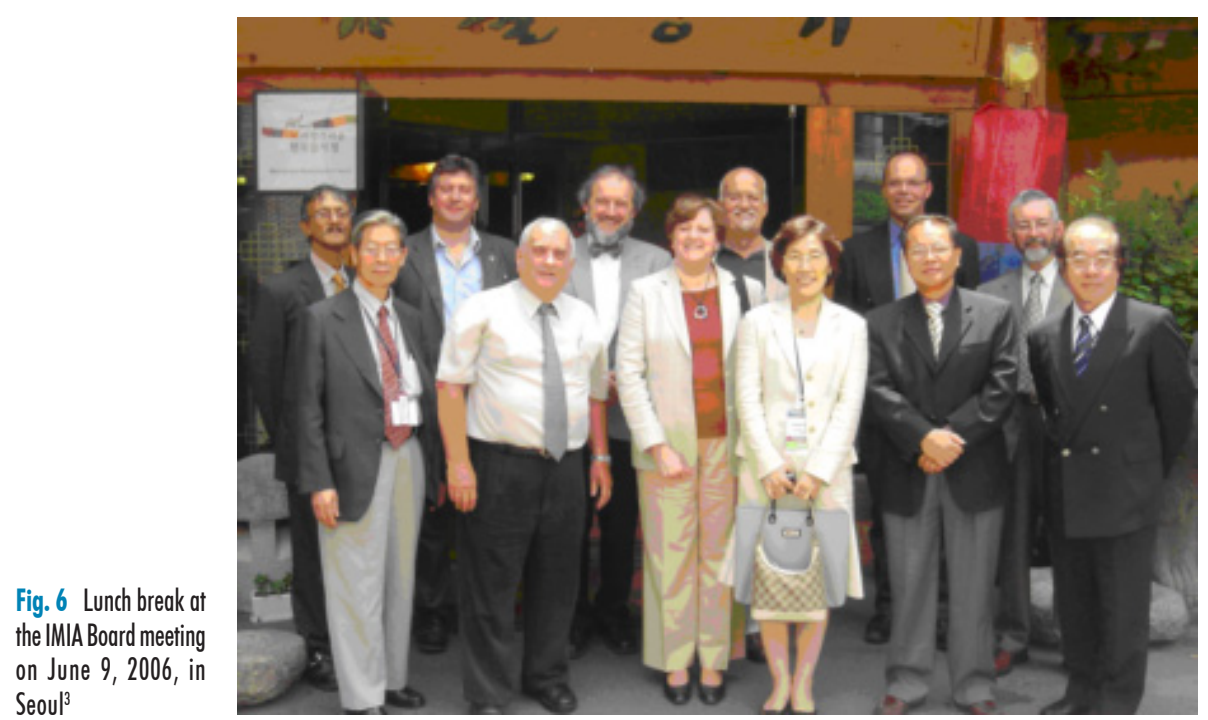

Around the year 2004 it became clear that the Yearbook in its current form was no longer timely. The new Yearbook as it is now differs in content and became a PubMed listed periodical. Also new technical solutions, including electronic access, and a new financial model had to be found. Without the support of the IMIA Presidents KC Lun and later Nancy Lorenzi as well as Dieter Bergemann as the publisher this transition would not have been possible. Steven Huesing's contributions, however, had been crucial. Without his active involvement, Casimir and I would not have been able to successfully make this change. It was Steven, who identified the necessary and appropriate financial and organizational solutions.

The second example: When I became IMIA President, one of my priorities was to find solutions for a more timely international conference portfolio. In a world, where medical informatics had become of growing importance, a world congress in this field, taking place only every three years, was no more adequate. The question was, how to find

From left: Sedick Isaaks, Yun Sik Kwak, Peter Murray, Assa Reichert, Reinhold Haux, Nancy Lorenzi, Steven Huesing, Hyeoun Ae Park, Antoine Geissbuhler, KC Lun, Diamuid UaConaill, Hiroshi Takeda ways to increase the frequency of our world conference MEDINFO, while considering other international conferences, mainly of our regional medical informatics organizations in The Americas, Asia, Europe etc.. It was necessary to find solutions for a joint future portfolio of these international medical informatics conferences, a portfolio, which suited the future needs. Many aspects play a decisive role for such a change, among other scientific quality, organizational aspects, and of course finances. With the help of many persons we found ways, how to start this change. Again Steven Huesing was the person, being able to shape and transform our ideas to a well-written memorandum, which could be presented in 2008 to IMIA's General Assembly and which showed us the way, what has to be done.

Steven very much enjoyed his home in Enderby, British Columbia, where he and Shirley Leonard lived since 2007. In our frequent phone and skype calls he often described the wonderful nature there. And Steven was a family person. I still remember a barbecue during MEDINFO 2007 in Brisbane, which he organized at his apartment. There he proudly introduced me to the many family members, who came to meet him there, in order to have joint holidays after our recent world congress. 
Haux et al.

During his last months Steven's health status was deteriorating. His efforts to prepare his last Board meeting in November 2007 in Buenos Aires were probably very high for him. Yet the meeting was well prepared and organized. From January on Peter Murray accepted to become Associate Executive Director of IMIA. He took over considerable parts of Steven's work, which then became urgently necessary. Still at this time I and many others wanted to share Steven's optimism that his health would soon become better again. Steven Huesing wrote in his email of March 12, 2009, on his presence at the next IMIA meetings "As it stands I will likely not be in Dublin [in April 2009], but I will be in Hiroshima! [in November 2009]".

\section{There is a Time for Everything}

Steven Huesing was an outstanding person and professional. As IMIA's Executive Director, he has for many years provided significant and global contributions to the progress of our field. Steven was IMIA's "motor". And, he was its ambassador. With him and through him international collaboration was done in a fair and respectful way. With Steven Huesing we have lost a valuable and leading colleague, and more than this, we lost an outstanding person and friend.

"There is a time for everything, and a season for every activity under heaven: a time to be born and a time to die" (Ecclesiastes 3). Steven, on behalf the many members of the IMIA family, who knew you:

Thank you, Steven, for what you have done.

More than this, thank you, Steven, for the many times we could be together with you.

Yes, there is a time for everything under heaven,

but we would have really liked some more years with you here on earth.

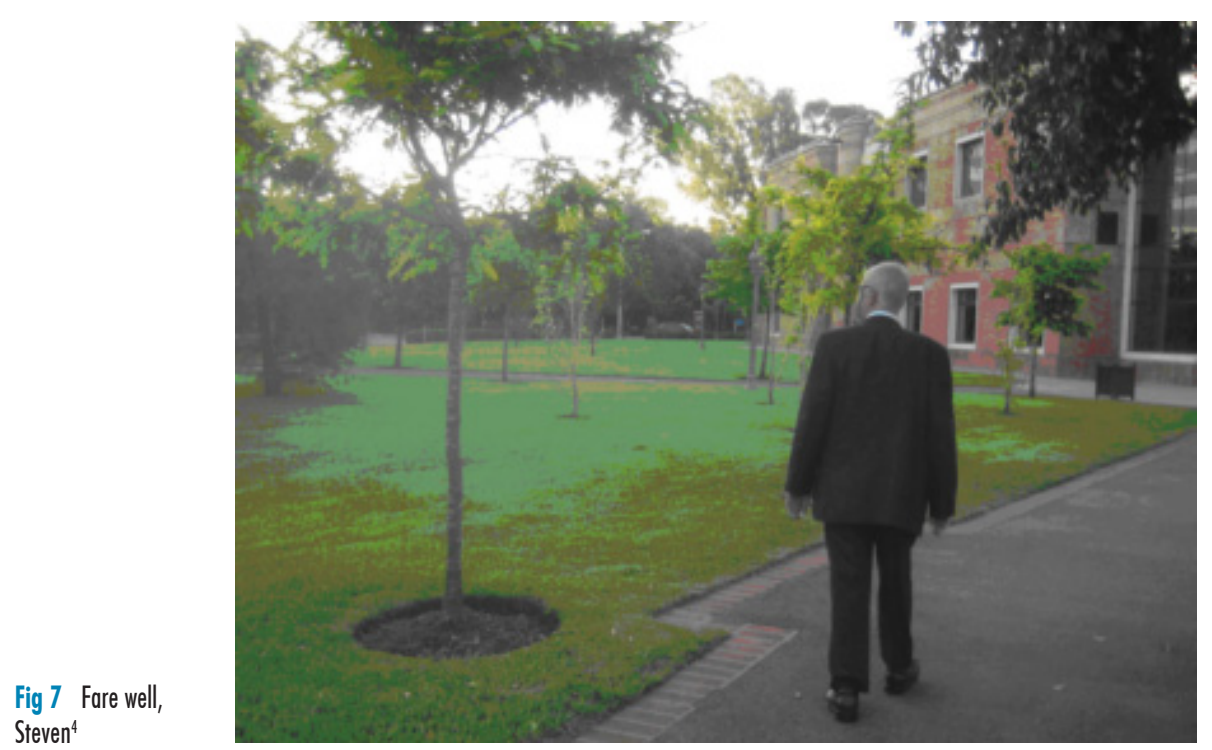

We will continue your work in your spirit.

Steven, be aware: You are gone. But you will be still with us.

\section{Acknowledgements}

We cordially want to thank Shirley Leonard and Elaine Huesing for sharing with us information on Steven's life.

\section{References $^{5}$}

1. Huesing SA. IMIA - a 40 year organizational overview. Yearb Med Inform 2007:186-91

2. Book of Condolence. From the "IMIA family" in memory of Steven A. Huesing. Prepared by Peter J Murray. April 20, 2009.

3. Health informatics industry pays tribute to IMIA's Executive Director Steven Huesing. Methods Inf Med 2008;47:III

4. HCIM\&C 2008;22(4).

5. Lorenzi NM. The IMIA possibility framework. Methods Inf Med 2004;43:207.

4 Picture taken October 30, 2008 at Pilar / Buenos Aires where "his" last IMIA Board meeting took place.

Besides the quoted references additional information has been taken from "his" magazine Healthcare Information Management and Communications Canada, www.HealthcareIMC.com, from itch.uvic.ca/ StevenHuesing.php and from www.longwoods.com/ view.php?aid=19430, last accesses June 10, 2009. The picture in figure 1 is taken from [6]. All other pictures are from the authors.
6. Huesing SA. Collaboration. HCIM\&C 2008;22(3):10.

Correspondence to:

Dr. Reinhold Haux

President, International Medical Informatics Association www.IMIA.org

Full Professor and Director

Peter L. Reichertz Insitiute for Medical Informatics

University of Braunschweig - Insitiute of Technology and

Hannover Medical School, Germany

Muehlenpfordtstr. 23

D-38106 Braunschweig

Germany

Tel: + 495313919501

Fax: + 495313919502

E-mail: Reinhold.Haux@plri.de

www.plri.de 